\title{
In Vitro Development of the Rare and Endangered Moss Molendoa hornschuchiana (Hook.) Lindb. ex Limpr. (Pottiaceae, Bryophyta)
}

Milorad Vujičić, Aneta Sabovljević ${ }^{1}$, and Jasmina Šinžar-Sekulić Institute of Botany and Garden, Faculty of Biology, University of Belgrade, Takovska 43, 11000 Belgrade, Serbia

\author{
Marijana Skorić \\ Institute of Biological Research "Sinisa Stankovic,'” University of Belgrade, \\ Bul. Despota Stefana 142, 11000 Belgrade, Serbia \\ Marko Sabovljević ${ }^{1}$ \\ Institute of Botany and Garden, Faculty of Biology, University of Belgrade, \\ Takovska 43, 11000 Belgrade, Serbia
}

Additional index words. bryophytes, critically endangered, gametophyte multiplication, growth regulators, in vitro culture, morphogenesis, mosses

\begin{abstract}
The high mountain pottioid moss Molendoa hornschuchiana (Hook) Lindb. ex Limpr. is a very rare and critically endangered bryophyte species in Europe in need for ex situ conservation. A 25-year-old herbarium sample was used to revive and propagate this species for further reintroduction and introduction to potential natural habitats. The reviving of "dead" herbarium specimen was achieved by disposing of axenical organisms as well as adjusting condition for developing secondary protonema, bud inductions, and optimization of gametophyte propagation in vitro condition. The influence of exogenously added growth regulators on the morphogenesis of this species was studied. The plants were cultured in the two basic types of media, viz., BCD and half-strength Murashige and Skoog (MS) supplemented with different concentrations (0.01-0.3 $\mu \mathrm{M})$ of indole3-butyric acid (IBA) and $\mathrm{N}_{6}$-benzyladenine (BA) under a 16-h photoperiod. The influence of growth regulators on gametophores multiplication in vitro as well as on protonemal diameter was recorded. Well-developed gametophores were obtained on BCD medium, whereas on half-strength MS medium, secondary protonema was produced, both on hormone-free and supplemented substrate exclusively. Based on multiplication index in vitro, maximum development of gametophores was realized on BCD medium supplemented with $0.3 \mu \mathrm{M}$ IBA and $0.1 \mu \mathrm{M}$ BA. However, the widest diameter of secondary protonema was obtained on BCD medium enriched with low concentration of both BA (0.01 and $0.03 \mu \mathrm{M})$ and constant concentration of IBA $(0.03 \mu \mathrm{M})$. Chemical names used: indole-

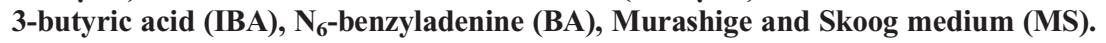

The technique of culturing plant tissues and organs under axenic conditions was first established and profitably used in bryophytes (mosses, liverworts, and hornworts), especially mosses (Lal, 1984; Servettaz, 1913). However, since then, comparatively little work has been carried out using bryophytes. Just a few mosses have been used to investigate the plant growth regulators' influence on their development in vitro (e.g., Funaria hygrometrica and $P$. patens; both from Funariales; Bijelović et al., 2004). However, bryophytes are interesting in

\footnotetext{
Received for publication 6 Sept. 2011. Accepted for publication 24 Oct. 2011.

This work is supported by the Ministry of Education and Science of the Republic of Serbia (Nos. 173024 and 173030).

We acknowledge the laboratory help of Miss Maja Simić.

${ }^{1}$ To whom reprint requests should be addressed; e-mail aneta@bio.bg.ac.rs.
}

growth regulator research not only because they have simple organ structure, but also because they respond to many plant growth regulators (Von Schwartzenberg, 2009), and not all tested species react the same way. Mosses provide excellent and very convenient material for in vitro culture and they are a very good experimental model for studies on basic molecular, cytological, and developmental plant biology (Duckett et al., 2004; Gonzales et al., 2006).

Molendoa hornschuchiana (Hook.) Lindb. ex Limpr., a moss species previously reported from mountainous areas of Europe, northern Africa, India, China, and Japan, is found in the New World at low elevations in the coastal Chugach Mountains of southern Alaska (Zander, 1979). Worldwide, the species is disjunct between mountainous areas with high annual precipitation in temperate climates. It is noted as threatened in many national or regional red lists (Montenegro, Germany,
Austria, Switzerland, Italy, Japan, e.g., Cortini Pedrotti and Aleffi, 1992; ECCB, 1995; Ludwig et al., 1996; Sabovljević et al., 2004; Schnyder et al., 2004) and in some countries (e.g., in Italy) it is even considered extinct.

However, bryophytes are often overlooked in conservation initiatives as diminutive, although some ex situ bryophyte collections exist (Rowntree, 2010; Rowntree et al., 2011). This is rather the result of low economical interest of bryophytes as well as the problems of establishing and maintaining stable in vitro culture (Sabovljević et al., 2003). So, protonema could remain in such a phase without passing to the next developmental stage if certain exogenous physical and/or chemical factors are not involved. Such an inducing factor is not always easy to define, and if known, it is not easy to adjust the intensity and duration of factor application.

The aim of this study was to establish an axenic culture and to examine the effects of growth regulators on in vitro development and propagation of rare and endangered pottiaceaous moss $M$. hornschuchiana [syn. Anoectangium hornschuchianum (Hook.) Funck ex Hornsch]. Because little work on growth regulator effects on bryophyte development in vitro has been carried out, this article presents novel data in this field. Also, propagated material has horticultural value because this moss can be used in Japanese moss gardens for ornamental and conservation purposes at the same time. The study purpose was to get better knowledge of this species biology and its input in ex situ conservation.

\section{Materials and Methods}

Plant material. Having in mind that $M$. hornsuchiana is a very rare and critically endangered species in Europe, the plant material from herbaria was used for establishing the in vitro culture. The material used was originally collected by G. Schwab in Canton Niedwelden on 12 Aug. 1985 and deposed in the BEOU bryophyte collection under No. 4336.

Establishment of gametophyte culture in vitro. Cultures were initiated from young vegetative gametophore shoots. The gametophore tips were cleaned and washed in running tap water followed by additional washes in double distilled water in a laminar flow chamber. They were then surface-disinfested with $10 \%$ commercial bleach (sodium hypochlorite) for $3 \mathrm{~min}$ and finally rinsed three times in sterile distilled water. We used half-strength MS (Murashige and Skoog, 1962) salts and vitamins, $100 \mathrm{mg} \cdot \mathrm{L}^{-1}$ myo-inositol, sucrose $\left(0.0\right.$ and $\left.15.0 \mathrm{~g} \cdot \mathrm{L}^{-1}\right)$, and $7.0 \mathrm{~g} \cdot \mathrm{L}^{-1}$ agar (Torlak purified, Belgrade, Serbia) as a medium composition for the establishment of $M$. hornsuchiana in in vitro culture. The $\mathrm{pH}$ of the media was adjusted to 5.8 before autoclaving at $121^{\circ} \mathrm{C}$ for $25 \mathrm{~min}$. To study the effects of sucrose, basal medium and growth regulators (IBA and BA) on the morphogenesis in terms of shoot induction and multiplication and protonemal development, the following treatments were tested: 1) half-strength MS medium without sucrose and 
growth regulators (MS/2); 2) half-strength MS medium supplemented with $15.0 \mathrm{~g} \cdot \mathrm{L}^{-1}$ sucrose (MS/2 S/2); and 3) BCD (Sabovljević et al., 2009) medium enriched with $15.0 \mathrm{~g} \cdot \mathrm{L}^{-1}$ sucrose (BCD). For shoot induction, different concentrations $(0.01,0.03,0.1$, and $0.3 \mu \mathrm{M})$ of IBA and/or BA were applied on all basal media. Cultures were grown at $25 \pm 2{ }^{\circ} \mathrm{C}$ under a 16 -h photoperiod at $47 \mu \mathrm{mol} \cdot \mathrm{m}^{-2} \cdot \mathrm{s}^{-1}$ photosynthetic photon flux density (provided by cool-white fluorescent tubes).

Data observations. For each treatment, shoot explants were cultured in $90-\mathrm{mm}$ petri dishes, each containing 10 explants. The effects of tested media types and growth regulators were evaluated by measuring the multiplication index, primary and secondary protonemal developments, and new bud formation. The multiplication index represents the number of newly grown shoots originating from newly induced buds on secondary protonema, which derived from one starting shoot. The microscope Leica DMLS and the stereomicroscope Leica MZ75 were used for observation.

Statistical analysis. For each treatment, there were four replications, each representing 10 gametophyte shoots of the same height $(1.0 \mathrm{~cm})$. The experiment was repeated twice. Data were analyzed by factorial three-way analyses of variance followed by the separation of mean values by Fisher's least significant difference test. The term significant was used to indicate differences for which $P \leq$ 0.05 .

Table 1. Influence of different media types (BCD, $\mathrm{MS} / 2 \mathrm{~S} / 2, \mathrm{MS} / 2$ ) supplemented with plant growth regulators (IBA and/or BA) on Molendoa hornschuchiana secondary protonema size (mm).

\begin{tabular}{|c|c|c|c|c|}
\hline \multicolumn{2}{|c|}{ Growth regulator $(\mu \mathrm{M}$} & \multicolumn{3}{|c|}{ Basal medium } \\
\hline IBA & BA & $\mathrm{BCD}$ & $\mathrm{MS} / 2 \mathrm{~S} / 2$ & $\mathrm{MS} / 2$ \\
\hline \multirow[t]{4}{*}{0} & 0.01 & $4.52 \mathrm{~cd}$ & $1.90 \mathrm{de}$ & $1.50 \mathrm{e}$ \\
\hline & 0.03 & $4.90 \mathrm{c}$ & $1.99 \mathrm{de}$ & $1.21 \mathrm{e}$ \\
\hline & 0.1 & $3.69 \mathrm{~d}$ & $2.08 \mathrm{de}$ & $1.11 \mathrm{e}$ \\
\hline & 0.3 & $3.56 \mathrm{~d}$ & $2.71 \mathrm{de}$ & $0.81 \mathrm{e}$ \\
\hline \multirow[t]{5}{*}{0.01} & 0 & $4.31 \mathrm{~cd}$ & $1.71 \mathrm{de}$ & $0.61 \mathrm{e}$ \\
\hline & 0.01 & $5.10 \mathrm{c}$ & $1.96 \mathrm{de}$ & $0.80 \mathrm{e}$ \\
\hline & 0.03 & $4.32 \mathrm{~cd}$ & $2.19 \mathrm{de}$ & $0.88 \mathrm{e}$ \\
\hline & 0.1 & $4.70 \mathrm{c}$ & $2.58 \mathrm{de}$ & $1.05 \mathrm{e}$ \\
\hline & 0.3 & $5.11 \mathrm{c}$ & $3.60 \mathrm{~d}$ & $1.21 \mathrm{e}$ \\
\hline \multirow[t]{5}{*}{0.03} & 0 & $4.40 \mathrm{~cd}$ & $1.81 \mathrm{de}$ & $0.72 \mathrm{e}$ \\
\hline & 0.01 & $29.00 \mathrm{~b}$ & $2.25 \mathrm{de}$ & $0.92 \mathrm{e}$ \\
\hline & 0.03 & $41.75 \mathrm{a}$ & $2.16 \mathrm{de}$ & $0.86 \mathrm{e}$ \\
\hline & 0.1 & $4.43 \mathrm{~cd}$ & $2.41 \mathrm{de}$ & $0.95 \mathrm{e}$ \\
\hline & 0.3 & $4.10 \mathrm{~cd}$ & $2.71 \mathrm{de}$ & $1.08 \mathrm{e}$ \\
\hline \multirow[t]{5}{*}{0.1} & 0 & $4.81 \mathrm{c}$ & $1.99 \mathrm{de}$ & $0.84 \mathrm{e}$ \\
\hline & 0.01 & $4.48 \mathrm{~cd}$ & $3.25 \mathrm{~d}$ & $0.51 \mathrm{ef}$ \\
\hline & 0.03 & $5.45 \mathrm{c}$ & $1.85 \mathrm{de}$ & $0.66 \mathrm{e}$ \\
\hline & 0.1 & $4.60 \mathrm{~cd}$ & $3.70 \mathrm{~d}$ & $0.85 \mathrm{e}$ \\
\hline & 0.3 & $4.86 \mathrm{c}$ & $2.57 \mathrm{de}$ & $0.80 \mathrm{e}$ \\
\hline \multirow[t]{5}{*}{0.3} & 0 & $5.61 \mathrm{c}$ & $2.11 \mathrm{de}$ & $0.91 \mathrm{e}$ \\
\hline & 0.01 & $4.38 \mathrm{~cd}$ & $3.14 \mathrm{~d}$ & $0.70 \mathrm{e}$ \\
\hline & 0.03 & $4.02 \mathrm{~cd}$ & $1.60 \mathrm{e}$ & $0.51 \mathrm{ef}$ \\
\hline & 0.1 & $4.77 \mathrm{c}$ & $3.09 \mathrm{~d}$ & $0.74 \mathrm{e}$ \\
\hline & 0.3 & $3.29 \mathrm{~d}$ & $2.44 \mathrm{de}$ & $0.42 \mathrm{ef}$ \\
\hline
\end{tabular}

Means separated by least significant difference (LSD) test $\left(\mathrm{LSD}_{0.05}=1.10, P<0.05\right)$. For each treatment, means followed by the same letter(s) are not significantly different.

MS = Murashige and Skoog; IBA = indole-3-butyric acid; $\mathrm{BA}=\mathrm{N}_{6}$-benzyladenine .

\section{Results and Discussion}

Secondary protonemal diameter was largest on BCD media containing sucrose compared with all other treatments. The highest secondary protonema diameter $(41.75 \mathrm{~mm})$ was observed when $M$. hornschuchiana was grown on BCD medium enriched with $0.03 \mu \mathrm{M}$ IBA and $0.03 \mu \mathrm{M}$ (Table 1). With increasing IBA concentrations without $\mathrm{BA}$ in the $\mathrm{BCD}$ medium, protonema diameter increased and optimal IBA concentration was 0.1 and $0.3 \mu \mathrm{M}$ (Table 1). However, with increasing BA content in the $\mathrm{BCD}$ medium, protonema diameter decreased.

The growth of protonema was more positively affected by addition of IBA and BA together in the BCD medium (Table 1). Protonema was up to six times larger on $\mathrm{BCD}$ medium enriched with low concentrations of BA $(0.01$ and $0.03 \mu \mathrm{M})$ and constant concentration of IBA $(0.03 \mu \mathrm{M})$ in comparison with all other applied phytohormone concentrations and different media types used (Table 1).

When M. hornschuchiana was growing on MS/2 medium, protonema diameter was smaller than on BCD medium (Table 1). Pro-
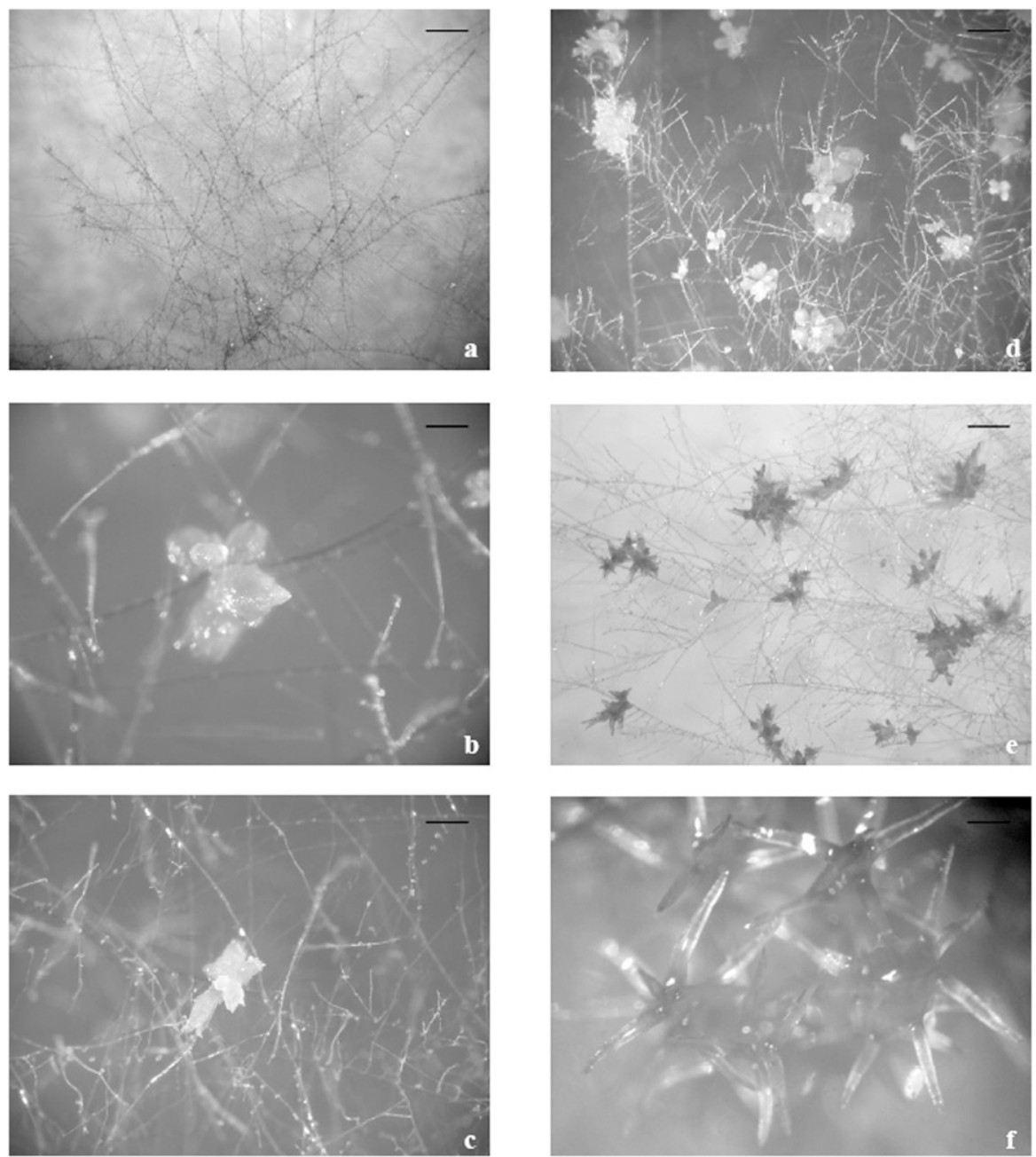

Fig. 1. Molendoa hornschuchiana developmental stages in in vitro culture, on BCD medium: (A) secondary protonema expansion, (B) bud formation on protonema, (C) bud formation and caulonemal development, (D) extensive bud production and caulonemal development, (E) early-stage gametophyte development, and (F) fully developed gametophyte i.e., haploid plants (bar size: $5 \mathrm{~mm}$ ). 


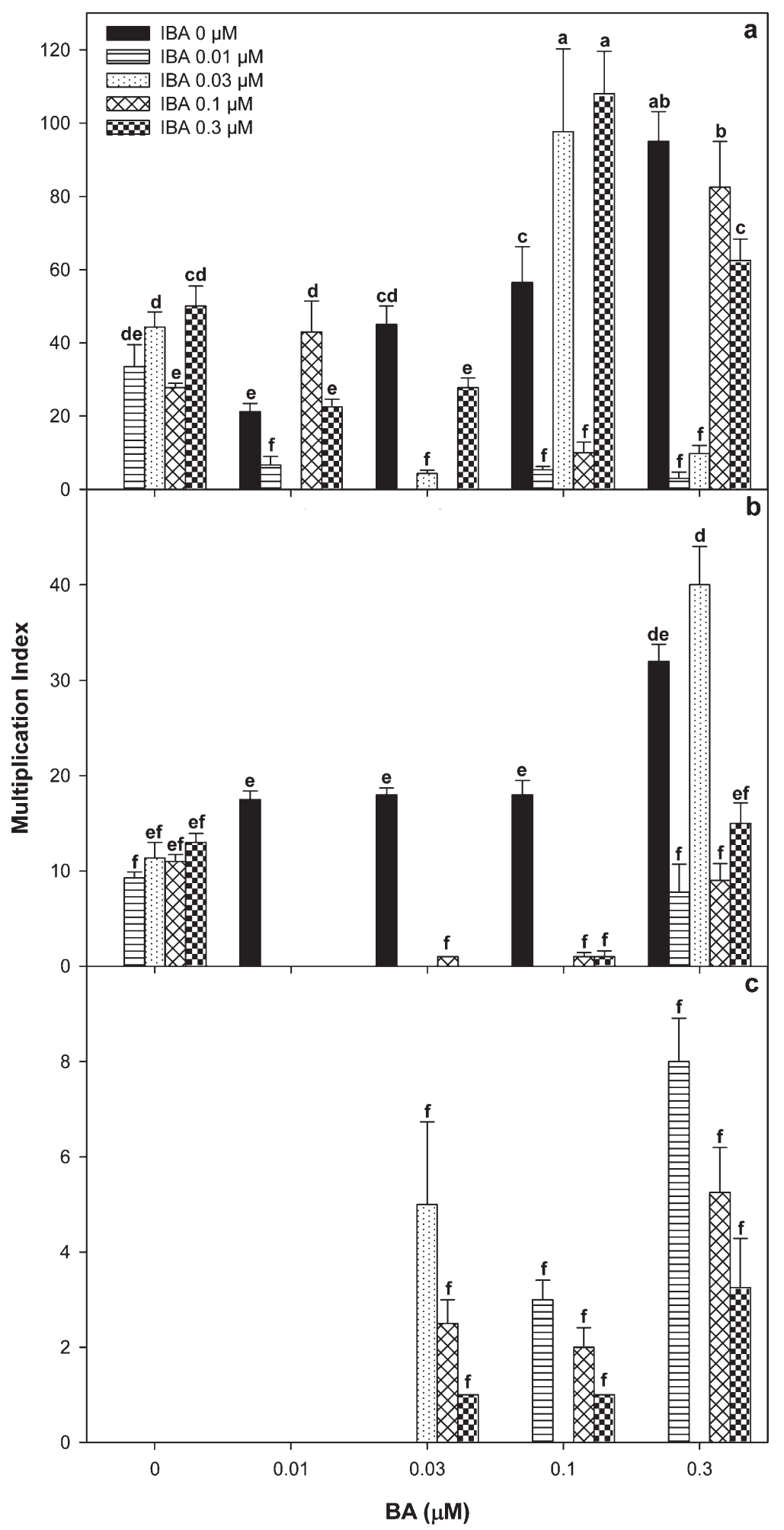

Fig. 2. Influence of different media types and plant growth regulators (IBA and BA) on Molendoa hornschuchiana multiplication in vitro. Culture period: 6 weeks. (A) BCD medium; (B) MS/2 S/2 medium; (C) MS/2 medium. Different letters above bars indicate significant differences among treatment according to least significant difference $(\mathrm{LSD})$ test $\left(\mathrm{LSD}_{0.05}=11.74, P<0.05\right)$ IBA $=$ indole-3butyric acid; $\mathrm{BA}=\mathrm{N}_{6}$-benzyladenine; $\mathrm{MS}=$ Murashige and Skoog.

medium types had a significantly lower index of multiplication (Fig. 2B-C). The highest multiplication index was detected when $M$. hornschuchiana was grown on $\mathrm{MS} / 2 \mathrm{~S} / 2$ medium enriched with $0.3 \mu \mathrm{MBA}$ and $0.03 \mu \mathrm{M}$ IBA (Fig. 2B). Also, plants grown on the same medium enriched only with $0.3 \mu \mathrm{M}$ BA had a similar multiplication index without significant differences (Fig. 2B). The growth regulator IBA, applied alone, did not have a positive effect on the multiplication of M. hornschuchiana shoots (Figs. 1C and 2B). Plants that were grown on the MS/2 had a significantly lower multiplication index in comparison with all other media types (Figs. 1E and 2C).

Auxins and cytokinins have basic functions in the regulation of normal bryophyte development. Previous investigations indicate that the hormonal system of mosses includes the sequential interaction of auxin and cytokinin as a main component (Bijelović et al., 2004; Bopp and Bhatla, 1985; Cove and Ashton, 1984). To date, the known effects of auxins on moss development include inhibition of protonema growth, stimulation of rhizoid formation, transformation of buds to filaments, torsion of young stems, complete suppression of leaves on gametophores, and callus induction (Bopp, 1955). Bud formation, the number of buds and their position along the caulonema, and cell division in protonema are determined by cytokinins. Although the effects on exogenously applied auxins and cytokinins on moss development were discovered many years ago, results are very scattered and related to a very low number of bryophyte species (mostly $P$. patens and $F$. hygrometrica). Bryophytes are a very diverse group of plants and it is important to include as much as possible different bryophyte species in research of plant growth regulator action on a morphogenetic and molecular level.

To understand the plant growth regulator effect in more detail, it is important to know more about such components as synthesis, metabolism, and transport. For this purpose, mutants have been introduced into moss research. The mutants with a low degree of auxin production are relatively insensitive to exogenously supplied cytokinins. It can be concluded that sensitivity to cytokinins for bud formation must be dependent on the presence of auxin, which must be present in higher concentration (Cove and Ashton, 1984; Schumaker and Dietrich, 1998).

The micropropagation of $M$. hornschuchiana was successfully applied on BCD medium supplemented with $0.3 \mu \mathrm{M}$ IBA and $0.1 \mu \mathrm{M}$ BA when gametophore production is counted. On BCD medium enriched with a low concentration of both BA $(0.01$ and $0.03 \mu \mathrm{M})$ and constant concentration of IBA $(0.03 \mu \mathrm{M})$, the highest production of secondary protonema was achieved.

\section{Literature Cited}

Bijelović, A., M. Sabovljević, D. Grubišić, and R. Konjević. 2004. Phytohormone influence on the morphogenesis of two mosses [Bryum argenteum Hedw. and Atrichum undulatum (Hedw.) P. Beauv.]. Isr. J. Plant Sci. 52:31-36.

Bopp, M. 1955. Die Entwicklung von Zelle und Kern im Protonema von Funaria hygrometrica Sibth. Planta 45:573-590.

Bopp, M. and S.C. Bhatla. 1985. Hormonal regulation of development in mosses, p. 65-87. In: Purohit, S.S. (ed.). Hormonal regulation of plant growth and development 2. Agro-Botanical Publishers, Old Ginanni, Bikaner.

Cortini Pedrotti, C. and M. Aleffi. 1992. Lista rossa della briofite d'Italia, p. 559-687. In: Conti, F., A. Manzi, and F. Pedrotti (eds.). Libro rosso delle piante d'Italia. WWW \& Soc. Bot. Italiana, Roma, Italy. 
Cove, D.J. and N.W. Ashton. 1984. The hormonal regulation of gametophytic development in bryophytes, p. 177-201. In: Dyer, A.F. and J.G. Duckett. (eds.). The experimental biology of bryophytes. Academic Press, London, UK.

Duckett, J.G., J. Burch, P.W. Fletcher, H.W. Matcham, D.J. Read, A.J. Russel, and S. Pressel. 2004. In vitro cultivation of bryophytes: A review of practicalities, problems, progress and promise. J. Bryol. 26:3-20.

ECCB. 1995. Red data book of European bryophytes. ECCB, Trondheim, Norway.

Gonzales, M.L., R. Mallon, J. Reinoso, and J. Rodrigues-Oubina. 2006. In vitro micropropagation and long-term conservation of the endangered moss Splachnum ampullaceum. Biol. Plant. 50:339-345.

Lal, M. 1984. The culture of bryophytes including apogamy, apospory, parthenogenesis and protoplasts, p. 97-115. In: Dyer, A.F. and J.G. Duckett (eds.). The experimental biology of bryophytes. Academic Press, London, UK.

Ludwig, G., R. Düll, G. Philippi, M. Ahrens, S. Caspari, M. Koperski, S. Lütt, F. Schulz, and G. Schwab. 1996. Rote Liste der Moose (Anthocerophyta et Bryophyta) Deutschlands.
Schriftenreihe für Vegetationskunde 28:189306.

Murashige, T. and F. Skoog. 1962. A revised medium for rapid growth and bioassays with tabacco tissue culture. Physiol. Plant. 15:473-497.

Rowntree, J.K. 2010. Development of novel methods for the initiation of in vitro bryophyte cultures for conservation. Plant Cell Tiss. Org. 87:191-201.

Rowntree, J.K., S. Pressel, M.M. Ramsay, A. Sabovljević, and M. Sabovljević. 2011. In vitro conservation of European bryophytes. In Vitro Cell. Dev. Biol. Plant 47:55-64.

Sabovljević, M., A. Bijelović, and I. Dragićević. 2003. In vitro culture of mosses: Aloina aloides (K.F. Schultz) Kindb., Brachythecium velutinum (Hedw.) B.S.\&G., Ceratodon purpureus (Hedw.) Brid., Eurhynchium praelongum (Hedw.) B.S.\&G. and Grimmia pulvinata (Hedw.) Sm. Turk. J. Bot. 27:441-446.

Sabovljević, M., T. Cvetić, and V. Stevanović. 2004. Bryophyte red list of Serbia and Montenegro. Biodivers. Conserv. 13:1781-1790.

Sabovljević, A., M. Sabovljević, and N. Jocković. 2009. In vitro culture and secondary metabolite isolation in bryophytes, p. 117-128. In: Jain,
S.M. and P.K. Saxena (eds.). Protocols for in vitro cultures and secondary metabolite analysis of aromatic and medicinal plants, Methods in molecular biology. Humana Press, New York. Schnyder, N., A. Bergamini, H. Hofmann, N. Müller, C. Schubiger-Bossard, and E. Urmi. 2004. Rote Liste der gefährdeten Arten der Schweiz. Hrsg. BUWAL, FUB \& NISM. BUWAL. Vollzug Umwelt, Reihe.

Schumaker, K.S. and M.A. Dietrich. 1998. Hormoneinduced signaling during moss development. Annu. Rev. Plant Physiol. Plant Mol. Biol. 49: 501-523.

Servettaz, C. 1913. Reserches experimentales sur le development et la nutrition des mousses en milieux sterilise. Ann. Sci. Nat. Bot. Biol. Veg. 17:111-223.

Von Schwartzenberg, K. 2009. Hormonal regulation of development by auxin and cytokinin in moss, p. 246-281. In: Knight, C., P-F. Perroud, and D. Cove (eds.). Annual plant reviews. Vol 36. The moss Physcomitrella patens. WileyBlackwell, UK.

Zander, R.H. 1979. Molendoa hornschuchiana new to the Americas from the Pacific coast of Alaska. Bryologist 82:487-489. 